\title{
Genomic Characterization of the Vaccinal Strain of Mycobacterium avium Subspecies paratuberculosis (MIP) 316F bv MIRU-VNTR
}

\section{Zahra Ebrahim (MSc)}

Department of Microbiology, Razi Vaccine \& Serum Research Institute, Karaj Iran and Rasht Branch of Islamic Azad University, Rasht, Iran

\section{Keyvan Tadayon (PhD)}

Department of Microbiology, Razi Vaccine \& Serum Research Institute, Karaj, Iran

Nader Mosavari (PhD)

Department of Microbiology, Razi

Vaccine \& Serum Research Institute,

Karaj, Iran

Corresponding Author: Keyvan Tadayon

Email: k.tadayon@rvsri.ac.ir

Tel:+989122148123

Address: Department of Microbiology, Razi Vaccine \& Serum Research Institute, Karaj, Iran

Received: 04 Apr 2015

Revised: 07 May 2015

Accepted: 15 May 2015

\section{ABSTRACT}

Background and Objective: Paratuberculosis is a chronic granulomatous enteritis of ruminants caused by Mycobacterium avium subspecies paratuberculosis (MAP). this study aimed to characterize the genome of the MAP 316F strain.

Methods: The MAP 316F strain was subjected to the PCR-F57 and PCR-IS900 experiments in order to ensure its identity as MAP. This was followed by application of the Thibault genotyping system consisting of eight loci including 292, x3, 25, 47, 3, 7, 10 and 32. Required genomic material for all experiments was prepared using the simple method of boiling. Gel electrophoresis findings related to the typing PCRs were backed by sequencing of amplification products.

Results: In PCR amplification, eight products with the size of 300, 298, 350, 217, 208, 203, 803 and 649 bp were detected at 292, X3, 25, 47, 3, 7, 10 and 32 loci, holding 3, 2, 3, 3, 2, 2, 2 and 8 copies of TRs at these loci, respectively.

Conclusion: This genomic pattern is matched with that of the MAP $316 \mathrm{~F}$ vaccine strain from the French Merial company and also the MAP K10 fully-sequenced strain.

Keywords: Mycobacterium Avium Subsp. Paratuberculosis, Genomics, Genotyping Techniques, Strain. 


\section{INTRODUCTION}

Mycobacterium avium subspecies paratuberculosis (MAP) causes chronic enteritis in ruminants known as paratuberculosis. In Iran, the very early cases of this disease date back to the period of 1962-65 when paratuberculosis was diagnosed in pure-bred cattle of the Abadan oil company herd, imported from the UK (1). Many Iranian scientists, believed that imported animals are to be blamed for initial introduction and dissemination of paratuberculosis in this country. Considering the latest available epidemiological reports, paratuberculosis is currently scattered throughout Iranian cattle and sheep population in all or majority of the country's territory (2-5). MAP bacteria have a fastidious nature and their laboratory culture demands long-incubation time which in primary isolation of human and sheep cases might even exceed a year (6). Besides, successful bacterial culture of the pathogen is conditional to Iron supplementation (mycobactin $\mathrm{J}$ ) of the culture medium. These difficulties have limited molecular epidemiological studies of MAP to fewer microbiology laboratories specialist in the field. Genomic studies have identified two principle classes (types) of MAP named sheep (S) and cattle (C) types. Molecular genomic methods have enabled the differentiation of these types $(7,8)$. In 2005, the result of fullgenome sequencing of MAP K10 was released to the public domain (9). This virulent strain was initially isolated in 1970's from a dairy herd in Wisconsin, USA. As many as 4,829,781 bp and over 3,000 homolog genes with those from Mycobacterium tuberculosis were characterized in the MAP K10 genome (9).

Over the last two decades, the IS900-RFLP turned into the most broadly used method in genotyping of MAP. In 2007, Thibualt pioneered in developing a variable number tandem repeat (VNTR) analyzing method based on 8 loci suitable for MAP genotyping. With receiving general acceptance from the scientific community, this method is turning to the standard protocol in epidemiological MAP Interspersed Repetitive Unit (MIRU) or VNTR analysis. To date 139 genotypes have been deposited in the European VNTR database of Mycobacterium avium complex in France (available at: mac-inmv.tours.inra.fr/) (10-14). MIRU-VNTR genotyping is a PCR-based system currently applied on numerous pathogenic bacteria (15-18) in which the copy number of specific genomic unit repeats, known as Tandem Repeats, in the genome of a given bacterium is determined. Depends on the copy numbers, size of the related genome segments differs among strains of bacterium. Technically, this is a straightforward and simple method that requires only a limited amount of genomic material with its simplified result format and amenable to digital processing and data-banking. These benefits have made MIRU-VNTR analysis superior compared to the older PFGE and RFLP genotyping protocols (19). In 1957, several laboratory MAP strains including $316 \mathrm{~F}$ were moved from the Weybridge Institute, UK to Razi Vaccine \& Serum Research Institute (RVSRI) by F. Entesar. Since then, MAP 316F has been used in production of paratuberculin (Johnin) and also paratuberculosis vaccine. More recently, this strain was resupplied to Razi by the Turkish collaborating center, Etlik.

Since the properties of MAP $316 \mathrm{~F}$ genome have not been yet studied, in this study the genomic characteristics of this strain have been analyzed by MIRU-VNTR typing.

\section{MATERIAL AND METHODS}

Culture of bacterial strain and extraction of the genome: Two Falcon tubes containing Herrold's egg yolk medium supplemented with mycobactin J (20) were inoculated with Etlik MAP 316F sub-strain to supply enough bacterial mass. Incubation at $37^{\circ} \mathrm{C}$ lasted for 12 weeks until bacterial growth became visible. Bacterial genome was obtained by boiling as described previously (20). Genomic experiments: All genomic experiments were PCR-based and conducted in consecutive groups of identification and genotyping tests. For identification, the IS900 and F57 MAP bacteria specific markers were implemented. In PCRIS900, Dohman's protocol (21) with few 
modifications and in PCR-F57, Schonenbrucher protocol (22) using newly-designed primers were performed as the original protocol was not adaptable to conventional thermocyclers. For genotyping, the Thibault protocol was selected and applied to the 6 loci of 7, 3, 37, 25, X3, 292. For the two remaining loci of 10 and 32, new primer pairs were designed and applied as difficulties in amplification with Thibault's primers were experienced. A $2 \mathrm{~kb}$ stretch of the MAP K10 genome flanking each of the loci was screened by Primer 3 version 4.0.0 (ftp://ftp.ncbi.nlm.nih.gov/genomes/) to design primers of choice $(23,24)$ (Table 1). For PCR amplification, all loci were individually subjected to a quad-protocol amplification experiment with 24 separate reactions. These protocols were designed in a way that 6 different annealing temperatures $(55,56.7,59.1,60.4$, 62.9 and64. ${ }^{\circ} \mathrm{C}$ ) were applied on PCR reactions containing 1 or $5 \mathrm{pmol}$ of forward/reverse primers (Macrogen ${ }^{\circledR}$, Korea) and 1 or $2.5 \mathrm{mM}$ concentrations of $\mathrm{MgCl}_{2}$. PCR reactions, set at $15 \mu 1$ volumes, contained a commercial master mix (Ampliquor®, Denmark). Double distilled PCR water was used as negative controls (Table 2). Gel electrophoresis of PCR products was performed using $1.5 \%$ multipurpose agarose gel, pre-stained with Redsafe $\AA$. Running of the loaded gels had continued for 2 hours at a 2 $\mathrm{V} / \mathrm{cm}$ electrical field. Optimization of PCR reaction ingredients and cycles: Three different ingredient protocols were adapted for PCRIS900, PCR-F57, the 6 MLVA-VNTR loci of 7 , 3, 37, 25, X3, 292 and the 32 and 10 loci (Tables 1 \& 2). Besides, two heating cycle protocols were developed; the first was applied to all experiments and the second was used only the 32 and 10 loci. The mixtures from reactions classified in the first group were subjected to an initial denaturation at $95^{\circ} \mathrm{C}$ for $5 \mathrm{~min}$ followed by 35 amplification cycles of $30 \mathrm{~s}$ at $95^{\circ}, 30 \mathrm{~s}$ at $61^{\circ} \mathrm{C}$ and $45 \mathrm{~s}$ at $72^{\circ} \mathrm{C}$ with a final extension treatment at $72^{\circ} \mathrm{C}$ lasting for $10 \mathrm{~min}$. For MLVA-VNTR 32 and 10 loci, the amplification process was started with a heat treatment at $94^{\circ} \mathrm{C}$ continued for $5 \mathrm{~min}$,followed by 35 consecutive cycles of $94^{\circ} \mathrm{C}$ for $1 \mathrm{~min}, 60^{\circ} \mathrm{C}$ for $30 \mathrm{~s}$ and $72^{\circ} \mathrm{C}$ for $30 \mathrm{~s}$ complemented with a single final extension step of $72^{\circ} \mathrm{C}$ for $5 \mathrm{~min}$. Precise sizing of PCR products and sequencing:extension treatment at $72^{\circ} \mathrm{C}$ lasting for $10 \mathrm{~min}$. For MLVA-VNTR 32 and 10 loci, the amplification process was started with a heat treatment at $94^{\circ} \mathrm{C}$ continued for $5 \mathrm{~min}$,followed by 35 consecutive cycles of $94^{\circ} \mathrm{C}$ for $1 \mathrm{~min}$, $60^{\circ} \mathrm{C}$ for $30 \mathrm{~s}$ and $72^{\circ} \mathrm{C}$ for $30 \mathrm{~s}$ complemented with a single final extension step of $72^{\circ} \mathrm{C}$ for 5 min. PCR products were sequenced in order to ensure the accuracy of gel electrophoresis results (Macrogen, South Korea). The raw data from sequencing were edited by Chromas Lite software version 2.1.1 (available on www.technelysium.com.au) and the nucleotide structure of products was precisely determined through in situ alignment of the complimented forward and reverse sequence strings using Clustal X software version 2.1 (available on www.clustal.org/clustal2/). Detection of unit repeats was achieved by running the Tandem Repeat Finder software version 4.04 (available on http://tandem.bu.edu/trf/trf.html). No adjustments were made to the software default settings. 
Table 1- primers used in this study

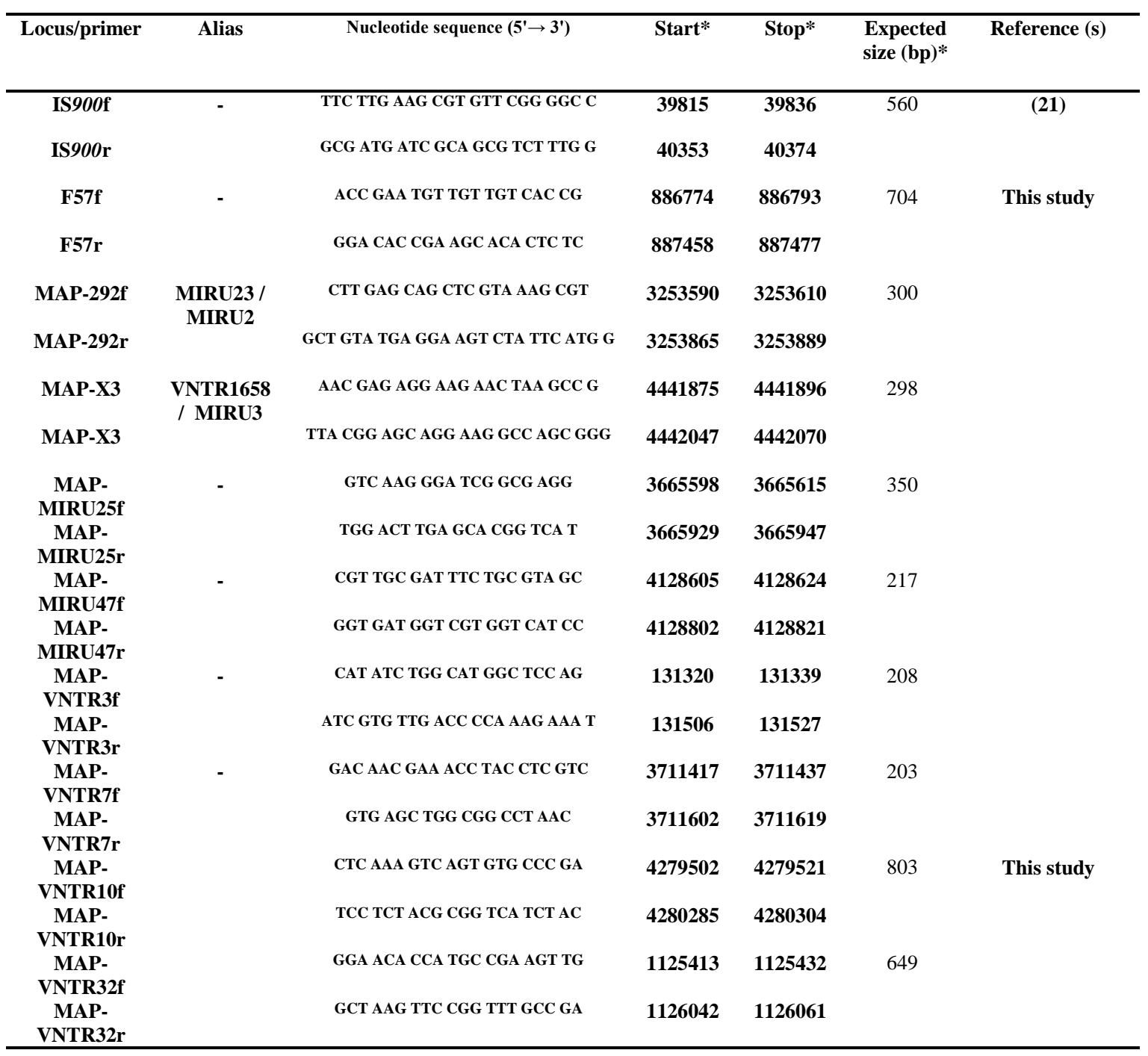

*MAP K10 genone

Table 2- PCR amplification ingredients used in this study

\begin{tabular}{|c|c|c|c|c|c|c|c|}
\hline PCR protocol & $\begin{array}{c}\text { PCR } \\
\text { master } \\
\operatorname{mix}(\mu \mathrm{l})\end{array}$ & $\begin{array}{c}\text { Primer } \\
\text { forward } \\
(5 \mathrm{pmol} / \mu \mathrm{l})\end{array}$ & $\begin{array}{l}\text { Primer reverse } \\
(5 \mathrm{pmol} / \mu \mathrm{l})\end{array}$ & $\begin{array}{c}\text { DNA } \\
\text { template } \\
(\mu \mathrm{l})\end{array}$ & $\begin{array}{c}\text { DMSO } \\
(\mu \mathrm{l})\end{array}$ & $\begin{array}{c}\text { PCR } \\
\text { water } \\
(\mu \mathrm{l}) \\
\end{array}$ & $\begin{array}{c}\text { Total } \\
\text { volume } \\
(\mu \mathrm{l})\end{array}$ \\
\hline IS900, F57 & 7.5 & 0.5 & 0.5 & 4 & 0.6 & 1.9 & 15 \\
\hline $292, X 3,25,47,3,7$ & 7.5 & 1 & 1 & 4 & 0.6 & 0.9 & 15 \\
\hline 10,32 & 7.5 & 0.25 & 0.25 & 5.25 & 0.6 & 1.15 & 15 \\
\hline
\end{tabular}




\section{RESULTS}

In PCR-IS900 and PCR-F57 amplification of MAP 316F, two fragments as large as $560 \mathrm{bp}$ and $704 \mathrm{bp}$ were produced respectively, to confirm its identity. In MIRU-VNTR typing of MAP 316F, gel electrophoresis findings, supported with sequencing, detected 8 fragments at PCR-VNTR292 (300 bp), X3 (298 bp), MIRU-VNTR 25 (350 bp), MIRU-VNTR 47 (216 bp), MIRU-VNTR 3 (208 bp), MIRUVNTR 7 (203 bp), MIRU-VNTR 10 (803 bp) and MIRU-VNTR 32 (649 bp). The outcome of data processing from running Tandem Repeat Finder on these loci detected 3, 2, 3, 3, 2, 2, 2 and 8 copies of the unit repeat at VNTR292, X3, MIRU-VNTR 25, MIRU-VNTR 47, MIRUVNTR 3, MIRU-VNTR 7, MIRU-VNTR 10 and MIRU-VNTR 32 loci, respectively. In a comparative in situ analysis of genomic data from MAP $316 \mathrm{~F}$ strain and those matching segments from the MAP K10 genome, no differences either in unit repeat numbers or single nucleotide polymorphism (SNP) was identified. Investigating the MAP MIRU-VNTR genotyping databank in France (http://macinmv.tours.inra.fr/) revealed that the MAP 316F strain genotype, INMV2, was already registered with the database.

\section{DISCUSSION}

Accurate identification and characterization of strains/isolates is a principle requirement in biological research and production settings. In 1920, at the Cornell University in the United States, a fast-growing mycobactin J independent laboratory isolate of Mycobacterium avium complex came to the attention. For almost half a century, this strain, known as MAP 18, was mistaken by the scientific community for MAP until 1968 when it was officially withdrawn from American Type Culture Collection (25). This historic fault indicates the importance of specific genetic markers in accurate identification of microorganisms. Despite the specificity of IS900 due to its high similarity with those named as IS900-like, characterization of MAP-suspected bacteria, solely based on IS 900 is prone to error $(26,27)$. Given the many years of archiving both
MAP $316 \mathrm{~F}$ and Mycobacterium avium subspecies avium D4 strains at Razi and efforts to address the concerning possible crosscontamination of these two, in this study two MAP specific markers of IS900 and F57 were simultaneously employed. Up to the present, some of the PCR-IS900 and almost all the PCRF57 based available strategies have been adapted to be used in real-time thermocyclers. These are typically expensive equipments which are not available in many veterinary microbiology laboratories. Moreover, genomic fragments of interest in real-time PCR are normally smaller than $100 \mathrm{bp}$ in length, rendering them hard to be characterized by conventional gel electrophoresis. In this study therefore, a new pair of primers was designed to amplify a larger fragment (350 bp) carrying the F57 element. Besides, by developing a single protocol both PCR-F57 and PCR-IS900 could be performed in one PCR run. At least two sub-strains of MAP $316 \mathrm{~F}$ are currently available, the British Weybridge and the French Merial sub-strains. In Thibault's study in 2007, both sub-strains were subjected to the MIRU-VNTR assessment and in consequence two different types were identified. The British sub-strain represented INMV17 (31332228) and the French sub-strain held INMV2 (32332228). While the Weybridge substrain genome carries a single copy of unit repeat at its X3 locus, genome of its Merial counterpart holds 2 copies of the unit repeat (6, 14). As it is represented here, the Razi sub-strain of MAP 136F, supplied by the Turkish Etlik Institute, similar to the French sub-strain, holds two copies of the unit repeat at its X3 locus. This similarity might be explained by a potential French supplier of the Turkish sub-strain or a mutual ancestor for both French and Turkish sub-strains. Since there is no data released on genotype of the Turkish sub-strain, we are unable to assess either of these scenarios.

\section{CONCLUSION}

F57 and IS900 are examples of genetic markers useful in laboratory identification of MAP isolates where long incubation periods and/or culture requirements hinder isolation and mass culture of bacterium. The Razi sub- strain 
of MAP $316 \mathrm{~F}$ is genetically different from its Weybridge ancestral sub-strain at locus X3. Since the Turkish Etlik institute is the supplier of the current strain at Razi, we assume the detected genomic changes might have materialized before its arrival to Razi.

\section{ACKNOWLEDGEMENTS}

This work received financial assistance from the Razi Institute under research grant number 2.18.18.94106. A.A. Shahmoradi, R. Keshavarz, M. Sekhavati and Sh. Dashtipour contributions

\section{References}

1.Baharsefat M, Amjadi A, Ahourai P, Yamini B, Entessar F, Hedayati H. Maladie de Johne (Paratuberculose) chez les Caprins et les Ovins en Iran. Arch Inst Razi. 1972; 24: 49-61.

2.Frothingham R. Evolutionary bottlenecks in the agents of tuberculosis, leprosy, and paratuberculosis. Med Hypotheses. 1999; 52(2): 95-9.

3.Ghaem Maghami S, Khosravi M, Ahmadi M, Denikoo A, Haghdin M, Koochakzadeh A. Study of the Prevalence Rate of John's Disease in Markazi Province and Evaluation of Absorbed ELISA for Adoption as a Diagnostic Method. Scientific-research Iranian Veterinary Journal. 2012; 8(3): 54-59.[Persian]

4.Hajikolaei M, Ghorbanpoor M, Solaymani M. The prevalence of Mycobacterium paratuberculosis infection in ileocaecal valve of cattle slaughtered in Ahvaz abattoir, southern Iran. Iranian Journal of Veterinary Research. 2006. 7(2): 77-80.

5.Sadati R, Jafarpour M, Mirinargesi M, Nazemi A, Barghi A. Prevalence of Mycobacterium avium subsp. paratuberculosis in dairy cattle bred in northern Iran by nested PCR. Global Vet. 2012; 8(3): 259-263.

6.Thibault VC, Grayon M, Boschiroli ML, Hubbans C, Overduin P, Stevenson K, et al. New variable-number tandem-repeat markers for typing Mycobacterium avium subsp. paratuberculosis and M. avium strains: comparison with IS900 and IS1245 restriction fragment length polymorphism typing. J Clin Microbiol. 2007; 45(8): 240410.

7.Collins DM, Gabric DM, de Lisle GW. Identification of two groups of Mycobacterium paratuberculosis strains by restriction endonuclease analysis and DNA hybridization. $\mathrm{J}$ Clin Microbiol. 1990; 28(7): 1591-6.

8.Stevenson K, Hughes VM, de Juan L, Inglis NF, Wright F, Sharp JM. Molecular characterization of pigmented and nonpigmented isolates of Mycobacterium avium subsp. paratuberculosis. J Clin Microbiol. 2002; 40(5): 1798-804.

9.Li L, Bannantine JP, Zhang Q, Amonsin A, May BJ, Alt $\mathrm{D}$, et al. The complete genome sequence of Mycobacterium avium subspecies paratuberculosis. Proc Natl Acad Sci U S A. 2005 ; 102(35): 12344-9.

10.Nacy C. Mycobacterium avium paratuberculosis: infrequent human pathogen or public health threat? Salem Massachusetts USA. 2008; 1-37.

11.Verdugo C, Pleydell E, Price-Carter M, Prattley D, Collins D, de Lisle G, et al. Molecular epidemiology of to this work are gratefully appreciated. Miss M. M. Haghighat and Mrs. N. Karimnasab are acknowledged for help with PCRs and sequencing. Zahra Ebrahim received her MSc degree in microbiology from Islamic Azad University of Rasht. We congratulate our colleagues on the occasion of the 90th anniversary of the Razi Vaccine \& Serum Research Institute in 2015.

\section{CONFLICT OF INTEREST}

Therer are no conflicts of interest.

Mycobacterium avium subsp. paratuberculosis isolated from sheep, cattle and deer on New Zealand pastoral farms. Prev Vet Med. 2014. 117(3-4):436-46. doi: 10.1016/j.prevetmed.

12.Sohal JS, Arsenault J, Labrecque O, Fairbrother JH, Roy JP, Fecteau G, et al. Genetic structure of Mycobacterium avium subsp. paratuberculosis population in cattle herds in Quebec as revealed by using a combination of multilocus genomic analyses. J Clin Microbiol. 2014; 52(8): 2764-75.

13.Fernandez-Silva JA, Abdulmawjood A, Akineden O, Drager K, Klawonn W, Bulte M. Molecular epidemiology of Mycobacterium avium subsp. paratuberculosis at a regional scale in Germany. Res Vet Sci. 2012; 93(2): 77682.

14.Stevenson K, Alvarez J, Bakker D, Biet F, de Juan L, Denham S, et al. Occurrence of Mycobacterium avium subspecies paratuberculosis across host species and European countries with evidence for transmission between wildlife and domestic ruminants. BMC Microbiol. 2009; 9: 212. doi:10.1186/1471-2180-9-212

15.Merdja SE, Khaled H, Aaziz R, Vorimore F, C Bertin, Dahmani A, et al. Detection and genotyping of Chlamydia species responsible for reproductive disorders in Algerian small ruminants. Trop Anim Health Prod. 2015; 47(2): 437-43.

16.Niemann J, Tietze E, Ruddat I, Fruth A, Prager R, Rabsch W, et al. Epidemiological analysis of the dynamic and diversity of Salmonella spp. in five German pig production clusters using pheno- and genotyping methods: an exploratory study. Vet Microbiol. 2015; 176(1-2): 1905.

17.Vodop'ianov AS, Mazrukho AB, Vodop'ianov SO, Mishan'kin BN, Kruglikov VD, Apkhangel'skaia IV, et al. VNTR-genotyping of Vibrio cholerae strains isolated from objects in the territory of Russian Federation in 2012. Zh Mikrobiol Epidemiol Immunobiol. 2014; 2: 46-51.

18.Zilber AL, Picardeau M, Ayral F, Artois M, Demont P, Kodjo A, et al. High-resolution typing of Leptospira interrogans strains by multispacer sequence typing. J Clin Microbiol. 2014; 52(2): 564-71.

19.Huang Y, Ke B, Sun J, He D, Chen Q, Ke C, et al. Molecular typing and surveillance on Salmonella typhimurium strain in Guangdong province, 2009-2011. Zhonghua Liu Xing Bing Xue Za Zhi. 2014; 35(8): 917-24.

20.Donaghy JA, Totton NL, Rowe MT. Evaluation of culture media for the recovery of Mycobacterium avium 
subsp. paratuberculosis from Cheddar cheese. Lett Appl Microbiol. 2003; 37(4): 285-91.

21.Dohmann K, Strommenger B, Stevenson K, de Juan L, Stratmann J, Kapur V, et al. Characterization of genetic differences between Mycobacterium avium subsp. paratuberculosis type I and type II isolates. J Clin Microbiol. 2003; 41(11): 5215-23.

22.Schonenbrucher H, Abdulmawjood A, Failing K, Bulte M. New triplex real-time PCR assay for detection of Mycobacterium avium subsp. paratuberculosis in bovine feces. Appl Environ Microbiol. 2008; 74(9): 2751-8.

23.Untergasser A, Cutcutache I, Koressaar T, Ye J, Faircloth BC, Remm M, et al. Primer3--new capabilities and interfaces. Nucleic Acids Res. 2012. 40(15): e115.
24.Ye J, Coulouris G, Zaretskaya I, Cutcutache I, Rozen S, TL Madden. Primer-BLAST: a tool to design targetspecific primers for polymerase chain reaction. BMC Bioinformatics. 2012; 13: 134. doi:10.1186/1471-2105-13134.

25.Chiodini R. The history of paratuberculosis (Johne's disease): A review of the literature 1895 to 1992. 1993.

26.Englund S, Bolske G, Johansson KE. An IS900-like sequence found in a Mycobacterium sp. other than Mycobacterium avium subsp. paratuberculosis. FEMS Microbiol Lett. 2002; 209(2): 267-71.

27.Harris JE, Lammerding AM. Crohn's disease and Mycobacterium avium subsp. paratuberculosis: current issues. J Food Prot. 2001; 64(12): 2103-10. 